\title{
"Political science searching for new thought": attractive raise of theme but not indisputable
}

\author{
M. Y. Mizulin ${ }^{1}$
}

${ }^{1}$ School Political Science, RANEPA, 82 Vernadsky Ave., Moscow 119571, Russian Federation

DOI: $10.18255 / 2412-6519-2020-3-238-249$

Research Article

Full text in Russian

This article explains the necessity of putting political thought at the center of political understanding of the world of the political phenomenon.

Author says that the formulation and the realization of scientific and educational projects and standards according the scheme «the unknown world - scientist exploring the unknown chaotic world-knowledge as the result of the scientific research of the scientist- publication of the gained knowledge/ introduction of the political discourse- transfer of the gained knowledge to the students and politicians» can work under modern circumstances only with a minimal efficiency or may not work at all.

In this particular situation the main and passing subject of the modern political education and scientific research should be political thought and it's projection into political action and reality.

This approach would supply the existing gap in the whole system of competences at which modern education and modern educational bodies should be oriented.

In the long-term perspective realization of this kind of program would require the constant methodological verification of basic principles and schemes of thought which were proposed by the representatives of the humanitarian knowledge at least for the last two centuries.

Keywords: political thought; political activity; understanding of political world

\section{INFORMATION ABOUT THE AUTHORS}

$$
\begin{array}{l|l}
\text { Mizulin Mikhail Y. } & \begin{array}{l}
\text { E-mail: mmizulin@mail.ru } \\
\text { Cand. Sc. (Philosophy), Associate Professor }
\end{array}
\end{array}
$$

For citation: Mizulin M. Y. "Political science searching for new thought": attractive raise of theme but not indisputable // Social'nye i gumanitarnye znanija. 2020. Vol. 6, No 3. P. 238-249. (in Russ.) 


\title{
«Политическая наука в поисках нового мышления»: привлекательность, но не бесспорность постановки темы
}

\author{
М. Ю. Мизулин ${ }^{1}$
}

${ }^{1}$ Школа политических исследований Института общественных наук, РАНХиГС, проспект Вернадского, 82, Москва, 119571, Российская Федерация

DOI: $10.18255 / 2412-6519-2020-3-238-249$

УДК 32

Научная статья

Полный текст на русском языке

В статье обосновывается необходимость постановки политического мышления в центр политического понимания мира и интерпретации мира политических явлений и феноменов.

Автор исходит из того, что постановка и реализация научных и образовательных проектов/стандартов по схеме «1. неизвестный мир - 2. ученый, познающий неизвестный хаотический мир - 3. знание как продукт научной деятельности ученого 4. публикация полученного знания/введение в политический дискурс - 5. трансляция полученного знания студентам и политикам» могут работать в современных условиях лишь с крайне минимальным коэффициентом полезного действия или вообще работать вхолостую.

В этой ситуации основным и сквозным предметом современного политического образования и научно-поисковой деятельности должно стать политическое мышление и его проективность в политическую деятельность и действительность.

Такой подход восполнит существующий пробел в общей системе компетенций, на которые должно быть сориентировано современное образование и современные образовательные учреждения.

В долгосрочной перспективе реализация такой программы потребует постоянной методологической верификации применительно к базовым принципам и схемам мышления, разрабатываемым представителями гуманитарного знания как минимум в последние два столетия.

Ключевые слова: политическое мышление; политическая деятельность; понимание политического мира

ИНФОРМАЦИЯ ОБ АВТОРАХ

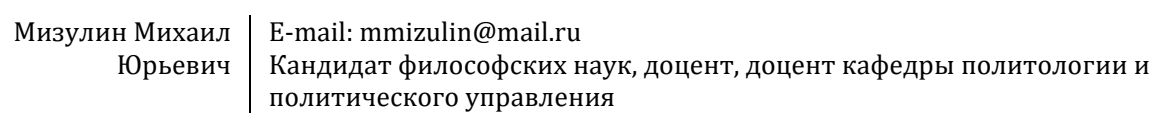

Для цитирования: Мизулин М. Ю. «Политическая наука в поисках нового мышления»:

привлекательность, но не бесспорность постановки темы // Социальные и гуманитарные знания. 2020.

Том 6, № 3. С. 238-249.

(С) Мизулин М. Ю., 2020

Статья открытого доступа под лицензией CC BY-NC-ND (http://creativecommons.org/licenses/by-nc-nd/4.0/)

Статья подготовлена на основании тезисов и выступления на Субботних политологических чтениях Школы публичной политики Института общественных наук РАНХиГС, прошедших 29 февраля 2020 года в Москве. 
Почему я назвал данную тематику субботних политологических чтений привлекательной, но не бесспорной?

Объясняю. Такое название чтений привлекательно своей относительной новизной.

Относительность новизны проявляется в том, что ещё в 1988 году М. С. Горбачев предложил новое мышление для нашей страны и всего мира [1], что подтверждает наличие такого предложения в новейшей политической истории СССР и России как правопреемнице СССР. При этом надо помнить, чем постановка такого вопроса завершилась - геополитической катастрофой в виде распада идеократического государства «Союз Советских Социалистических Республик».

Сказанное, в свою очередь, не означает, что наши субботние чтения могут претендовать на нечто подобное. Нет, конечно. Мы, увы, не субъекты реального политического действия и ни в коей мере не можем быть соразмерны масштабности личности М. С. Горбачева, который данную повестку поставил и привнёс в политическую жизнь страны. Мы в этом смысле «никто» по сравнению с ним, и это надо понимать, начиная обсуждать эту тему.

Однако у многих из нас, а именно у тех, кто наделен даром и способностью политического мышления, всегда есть существенное преимущество перед реальными политиками. У нас есть время мыслить и про-мысливать ту или иную политическую ситуацию, при этом неважно чью - свою или чужую.

Исходя из этого, утверждаю, что формулировка «Политическая наука в поисках нового мышления» далеко не бесспорна.

Такая формулировка с неизбежностью диктует следующие вопросы:

1. О какой политической науке идет речь, которая находится в поиске нового мышления?

2. Кто эти ученые и каковы школы научной политической мысли, которые этим занимаются?

3. Каков их метод и инструментарий?

4. Каковы результаты такого научного поиска?

Без ответов на вышеперечисленные вопросы все рассуждения становятся беспредметными.

Однако более спорным является предположение или утверждение, что вообще можно поисковым инструментарием политической науки «найти» новое мышление.

Кстати, новое мышление уже найдено и найдено не политиками и не политическими экспертами. Оно определено соавторами и со-деятелями технологической революции 4.0, в активную стадию которой вступило человечество [2].

В этой связи следует согласиться с авторами доклада Римского клуба, что всем нам необходимо пересмотреть всю источниковедческую модель, в значительной мере отказавшись от чтения и попыток научения студентов по литературе, изданной вплоть до настоящего времени.

Нельзя в современном мире учиться по книгам 1950-х годов, которые основаны на теориях 1850-го года.

Надо читать и рассматривать в качестве собственной мыслительной базы труды Эрнста Вайцзеккера [3], Андерса Вийкмана [4, р. 220], Германа Дэйли [5, 
P. 24-29], Рэя Курцвейла [6, с. 400], Питера Диамандиса [7], экологическую энциклику папы Франциска [8], визионерские прозрения Грегори Бейтсона [9, с. 347], теорию аутопоэза Умберто Матураны и Франциско Варелы [10], «системное видение жизни» Фритьофа Капры и Пьера Луиджи Луизи [11, p. 500], феноменологическую «биологию чуда» Андреаса Вебера [12], гендерные труды Рианы Айслер [13], исторические воззрения Г. В.Ф.Гегеля и Кена Уилбера [14], религиозные воззрения вице-президента Международного суда Кристофера Вирамантри [15] и монаха-бенедиктинца Дэвида Стайндл-Раста, перспективные подходы «Всемирного совета будущего» (World Future Council) Якоба фон Искулля [16] и «Великий переход» (Great Transition) Пола Раскина [17], альтернативные модели экономики Джереми Рифкина [18, с. 410], Кристиана Фельбера [19], Джона Фуллертона [20] и Гюнтера Паули [21] и при этом культивировать интегральное мышление, а не ограничиваться мышлением аналитическим и мышлением системным.

Все это нужно делать для понимания современного мира. Хотя, конечно, придерживаясь принципа «экономии мышления и деятельности», можно замкнуться в себе, разорвать коммуникацию с внешней для себя средой и предаться исключительно творению и решению другой задачи.

Такой задачей, существующей параллельно интеллектуальному процессу освоения современного миропонимания или без оного, является культивирование и постановка в сферу действительности конструкта (базовой политической единицы) политического мышления и основанной на нем схемы/схем политической деятельности. Подчеркну, не поиск нового мышления, а разработка проектов и программ понимания и масштабирования именно политического мышления - вот что необходимо делать и осуществлять применительно к ситуации современного мира и мерцающего или утверждающего свою сущность мира политического действия.

Дело в том, что постановка и реализация научных и образовательных проектов/стандартов по схеме «1. неизвестный мир - 2. ученый, познающий неизвестный хаотический мир - 3. знание как продукт научной деятельности ученого - 4. публикация полученного знания/введение в политический дискурс - 5. трансляция полученного знания студентам и политикам» может работать в современных условиях лишь с крайне минимальным коэффициентом полезного действия или вообще работать вхолостую.

Это тема отдельного симпозиума, которая достаточно рельефно прописана и обозначена О. В. Гаман-Голутвиной в статье «Преодолевая методологические различия: споры о познании политики в эпоху неопределенности» [22].

Соглашаясь с О. В. Гаман-Голутвиной в попытке проблематизации темы, отметим, что в современной эпохе неопределенности интеллектуальному сообществу необходима переориентация на «импульс жизни», а не на «древо познания добра и зла» [23], которая, в свою очередь, диктует переход (или частичный отказ от «голого сциентизма») на платформу разработки и постановки тренда политического мышления и деятельности.

В этом меня убеждает личный опыт пятилетнего срока разработки и администрирования образовательных программ для высших должностных лиц субъектов РФ в 2008-2013 годах, реализованных в РАГС/РАНХиГС на основании 14 распоряжений Президента РФ применительно к группам и потокам, включавшим 189 президентов республик в составе РФ и губернаторов. 
Ни один из вышеперечисленных образовательных проектов не смог с минимальной долей вероятности даже допустить возможность участия в такой программе хоть одного (за исключением ректора РАНХиГС В. А. Мау) ученого-политолога или ученого экономиста/правоведа.

Чистое знание или публично доступное знание, которое демонстрируется внутри политологического сообщества, реальным политикам не нужно. Ими оно и не востребовано.

Практическое (реализуемое) политическое знание большинству коллег-политологов в принципе не доступно и не понятно по существу. Схему такого знания, разработанную, например, А. М. Пятигорским, практически никто не знает, не внедряет и не обсуждает [23]. Многие делают нечто, в лучшем случае понятное самому себе. При этом оно, такое знание, не только не востребовано политиками и, как следствие, объективной политической реальностью, но и не продаваемо и не реализуемо на рынке образовательных услуг.

В этой ситуации основным и сквозным предметом современного политического образования и научно-поисковой деятельности должно стать политическое мышление и его проективность в политическую деятельность и действительность.

Такой подход позволит произвести различение политического и неполитического мышления, а именно: юридического, военного, экономического, предпринимательского, финансового, социального, педагогического и культурно-исторического типов мышления.

Все сопутствующие дисциплины и практики, в полном объеме позволяющие объективировать политический плацдарм (политическое поле=политический объект), должны быть увязаны с состояниями политического мышления. Только так в конечном счете можно сформировать политическое мышление, встроенное в суверенную/несуверенную государственную политику и формирующее эффективное политическое действие.

Такой подход восполнит существующий пробел в общей системе компетенций, на которые должно быть сориентировано современное образование и современные образовательные учреждения.

В долгосрочной перспективе реализация такой программы потребует постоянной методологической верификации применительно к базовым принципам и схемам мыследеятельности, разрабатываемым мыслителями как минимум в последние два столетия, о чем убедительно говорится в тезисах Л. В. Сморгунова ${ }^{1}$, представленных на чтения.

Таким образом, наша общая ситуативная задача состоит не в поиске «нового мышления», а в определении и постановке в качестве центра исследовательской работы онтологической картины современного политического мышления и построенного на нем политического действия или политического действия (деятеля), творящего политическое мышление, которое может быть размещено на технологической платформе революции 4.0.

\footnotetext{
${ }^{1}$ Как точно заметил на чтениях Л. В. Сморгунов, «Двадцатый век обострил тему соотношения интеллектуального (способность знать) и философского (способность думать) мышления в политике (Л. Штраус, А. Кожев, Х. Арендт)» // Тезисы субботних политологических чтений. Москва, 29.02.2020.
} 
Новое мышление современной технологической революции, осуществляемой прежде всего технологическими предпринимателями, с неизбежностью требует создания адекватной этому процессу платформы политического мышления, на базе которой возможно пере-учреждение государства и его институтов, утверждение компетенции «политик», радикальный пересмотр и изменение действующего образовательного стандарта в сфере политического знания, создание профессионального стандарта «политик» и сферы его институализации или, как модно говорить, «профессиональной инфраструктуры».

Сама же работа по платформатизации политического мышления, с нашей точки зрения, возможна только при определении исходных постулатов «политического мышления», воспроизведение которых ярко иллюстрирует, например, одна из исследовательских работ [24], посвященная анализу метода политического мышления Ханны Арендт ${ }^{1}$.

Итак, метод политического мышления Х. Арендт, проанализированный Э. Волларстом, включает следующие константы:

1. «Политическое мышление Ханны Арендт рассматривает темы в политическом поле не как «объект», а как феномен и явления. Это то, что отражается, предстает перед глазами и ощущается чувствами. Феномен заключается в том, что он «включает» тех, кто его наблюдает в пространстве, где он происходит, определяя отношения между феноменом и наблюдателями.

Политические события - это феномен в особом смысле, можно сказать, они сами по себе являются явлениями. Ибо они не появляются в пространстве сами по себе, подобно природным явлениям. А также само пространство не появляется перед наблюдателями, как это происходит с другими явлениями, например, в сфере искусства. Пространство, в котором происходят политические явления, создается самими явлениями. Или, если обозначить более точно, то оно создается лицами, деяния которых творят политические события. Следовательно, внешнее пространство является полным взаимодействием между людьми, предметами и отношениями. Наблюдатель, вступивший в данное пространство, имеющий отношение к людям, предметам и взаимоотношениям, по сути, связан с ними и принадлежит им. Вовлечение его во взаимоотношения может происходить лишь в том случае, если это отражается на политическом явлении как следствие проявления политических действий человека и последствий этих действий среди политиков, предметов и взаимоотношений. Наблюдатель должен определить политический феномен, т. е. он должен общаться с другими акторами или наблюдателями относительно пространства политических явлений, созданных политиками, предметами, и о том,

\footnotetext{
${ }^{1}$ При этом только на первый взгляд может показаться излишним достаточно обширное цитирование текста работы Эрнста Волларста «Ханна Арендт и метод политического мышления», опубликованной в 2018 году.

При более внимательном анализе современной теоретической ситуации следует согласиться с тем, что такой подход оправдан в силу целого ряда причин. Во-первых, в отечественной мысли мы не найдем работ по теме политического мышления, написанных политологами, ссылки на которые бы позволили обосновать данное направление научной мысли. Во-вторых, ссылка на разработки Ханны Арендт объясняется признанностью и авторитетом мыслителя в мировой политической культуре. Всемирный авторитет Х. Арендт сегодня таков, что практически всё, что написано ею, интересно широкой общественности и исследователям. И, наконец, в-третьих, при подготовке к формированию таких концептов, как политическая феноменология и политическая герменевтика, на что в некоторой мере претендует данная статья, следует признать предельно значимым введение в русскоязычный дискурс максимально широкого ракурса текста работы, анализирующей метод политического мышления Х. Арендт.
} 
как это пространство сохраняется, изменяется, упраздняется или разрушается. Феномен политического пространства создается, сохраняется, изменяется, отменяется и уничтожается участием (или неучастием) в данном пространстве посредством действия или коммуникации осуществляющими лицами, т. е. по их взаимному признанию, их действиями, их выступлениями и всем тем, на чем зиждется весь мир» [24, с. 163-164].

2. «Все политические события происходят в пределах феноменального пространства - мира. Возникает вопрос, каким образом эти явления попадают в свое пространство? Первый ответ на этот вопрос: из небытия. Это небытие не может быть онтологически определено теми метафизическими методами, которые пытаются осмыслить даже небытие. Политические явления возникают в своем пространстве из непрозрачной и непроницаемой тьмы, которая является человеческим сердцем. Навсегда закрытая для «научного» исследования, она еще может быть озарена проницательностью поэтов. Ханна Арендт никогда не делилась необоснованным презрением к поэтической проницательности со стороны тех, кто превозносит точность «научных» утверждений истины. На самом деле, ее интерпретационные труды относительно поэзии являются одними из самых красивых ее произведений. Что касается поэтически обозначенной тьмы, в которой политическая сфера имеет свое окончательное происхождение, то она лежит вне пространства политических явлений. Следовательно, эта крайняя тьма никогда - ни при каких обстоятельствах -сама по себе не является чем-то политическим» [Там же. С. 166].

3. «Политически это означает, что все человеческие события происходят в человеческих действиях. Такие действия человека - будь то действия отдельных людей, многих или всех, - выходят из темноты с целью, чтобы войти в мир. Он появляется в мире как нечто новое, как начало без логически прослеживаемого прецедента. С политической точки зрения, человек - это его собственное оружие и его собственное происхождение. Уточняя цитату из Сент-Огастина в конце книги «Истоки тоталитаризма», Ханна Арендт заявляет: «Человек обладает не только способностью творить начало, но он является самим началом. Если творение человека совпадает с сотворением начала Вселенной (а что еще это значит, кроме сотворения свободы?), тогда рождение отдельных людей, будучи новыми началами, вновь подтверждает изначальный характер человека, соответственно, что происхождение никогда не может стать полностью событием прошлого» [Там же. С. 168].

4. «Таким образом, действие - это явление в том смысле, в каком оно здесь обозначено: действие - это политическое явление. Концепт придуман Ханной Арендт для этого явления «рождаемости», и с помощью этого понятия она пытается понять феномен политического мира. Эта концепция - как и все остальные в мышлении Ханны Арендт - формируется не просто логическими операциями и методическими правилами. Она выходит из области явлений в их пространстве. То, что сама Ханна Арендт сказала о мышлении в политической сфере, относится и к ее собственным концепциям» [Там же. С. 169].

5. «Сама мысль, в той или иной мере, обладает большим потенциалом, чем техническая логическая операция, которую выполняют электронные машины, они лучше оснащены технически, нежели чем человеческий мозг. Мысль возникает вследствие происшедших инцидентов и событий жизненного опыта, которые должны оставаться его ориентирами, с помощью которых он берет свои тяготы 
и заботы, чтобы не потеряться в высотах, когда происходит полет фантазии или когда необходимо спуститься в глубины своего «Я». Другими словами, кривая, отражающая деятельность мысли, должна сохранять связь с инцидентом, точно так же, как круг связан с его фокусом; и единственное преимущество, которое можно было бы ожидать от самых загадочных явлений человеческой деятельности, заключается не в определениях и не в теориях, а, скорее, в процессе постепенного открытия и, возможно, социологического исследования региона, где произошел тот или иной инцидент и был полностью освещен в мгновение ока» [Там же].

6. «Политические события необъяснимы, если под объяснением подразумевается причинно-следственная связь. Они непостижимы, если понимание подразумевает соответствие понятиям, методически обозначенным посредством теоретических конструкций. Но это не означает, что мы не можем подходить к политическим событиям с пониманием. Такая неспособность означает, что мы не можем жить в мире, в котором мы сами создаем что-то новое, неожиданное и экстраординарное. Не все человеческие события подвержены слепому шансу, ибо такой шанс является лишь лицевой стороной такой же слепой необходимости, и указанное выше отношение никоим образом не означает химеру политического «десиционизма» [Там же. С. 170].

7. «Понимание суждения не следует путать с логическими операциями теоретических методов, результатом которых является знание. Объективное знание неспособно адекватно удовлетворить эти события, потому что оно не затрагивает изначальный характер этих явлений. Для объективного знания нет ничего нового под солнцем, то есть на земле. Понимание связано прежде всего со способностью, которая называла воображение, способность представить что-то отсутствующее как присутствующее и что-то присутствующее как отсутствующее. Реализация этого потенциала является одним из существенных условий для другого потенциала, который профессиональные философы назвали мышлением. Что бы ни говорили о мышлении как о профессиональной деятельности, нет необходимости оставлять нескольким профессионалам, если неспособность думать, бездумность может привести к тому, что человек больше не может представить результат и последствия своих действий. Последствия бездумности, существующей в мире, есть распространение глупости как недостатка» [Там же. С. 176].

8. «В этой ситуации глупость в кантианском смысле стала немощью каждого, и поэтому ее больше нельзя использовать как «выходное средство». «Глупость стала такой же распространенной, как и раньше, и это не означает, что она является симптомом массового общества или что «разумные» люди освобождены от нее. Единственное отличие заключается в том, что глупость остается блаженно бестолковой среди неинтеллектуальных и становится непоколебимой среди «разумных» людей. В интеллигенции можно даже сказать, что чем разумнее человек, тем больше раздражает его глупость, которую он разделяет со всеми» [Там же].

9. «Мышление как возможная деятельность людей, живущих в мире, оказывает замечательное влияние на мирские дела. В отличие от логических операций расчетных процессов («расчет последствий» Хоббса), мышление неизбежно связано с воображением. Поэтому оно способно растворить все наши фиксированные домыслы о том, что хорошо, красиво и т. д., и, возможно, для того, чтобы очистить нас 
от неисследованных предрассудков, которые мы потребовали через обычай и привычку. Однако мышление в его чистой и обособленной форме может полностью уйти от мирских дел и вернуться в царство, где не происходит никаких явлений: во всех его существенных аспектах, мышление аполитично. В самом деле, это может даже поставить под угрозу политическую сферу, если она используется теми, кто готов применить абстрактные выводы их мышления к практическим вопросам мира: «Если мы не можем определить, что такое благочестие, давайте быть нечестивыми» [Там же. С. 177].

10. «Мировоззрение, сформировавшееся из чистого мышления и его отдаления от явлений мира, враждебно по отношению к миру в своей феноменальности. Отказ от явлений также приводит к обобщениям, которые уничтожают частности, придерживаясь явлений. Безысходность является позитивной силой негатива, против которой не может преобладать никакое реальное событие. Чистое мышление забывает о собственном происхождении в воображении» [Там же. С. 179].

11.«Тем не менее вид мышления, имеющий память об этом происхождении, способен созерцать явления. Сила мышления способна растворить все, что зафиксировано и установлено, а затем продолжает функционировать против неисследованных предрассудков и предвзятых понятий, возрождающих явления, которые пытаются упорядочить все новые происходящие события в традиционных рамках. Мышление, связанное с воображением, позволяет представить что-то новое и ощутить это» [Там же].

12. «Когда все бездумно отметают все, что делают другие и во что верят все остальные, думающие начинают появляться из своего укрытия, поскольку их отказ присоединиться бросается в глаза и, таким образом, это становится своего рода их действием. Очищающий элемент в мышлении, рожденный Сократом, который выявляет последствия неисповеданных мнений и тем самым уничтожает их - ценности, доктрины, теории и даже убеждения, - имеет политическое значение. Поскольку это разрушение оказывает освободительное воздействие на другую человеческую способность - способность суждения, которую можно назвать, с некоторым оправданием, самыми политическими умственными способностями человека. Эта способность позволяет судить особенности, не подчиняя их в соответствии с теми общими правилами, которые могут быть научены и изучены, пока они не вырастут в привычки, которые могут быть заменены» [Там же. С. 180].

13. «Такое мышление направлено на мир и его явления и основывается на их реальности, тем самым обретая собственную реальность. Чистое мышление, следовательно, трансформируется в осуждение и осужденное понимание» [Там же].

14. «Основой для таких суждений является не тот опыт, получающий вследствие ясного мышления. В основе лежит мир, в котором мы сосуществуем с другими людьми, и существует опасность, когда ясная логичность занимает место данного опыта общей реальности в мире. Ибо эта логичность связана только с процессом наших ментальных функций, которые одинаково происходят для всех представителей человеческого рода. Эта идентичность ментальных функций совершенно отличается от общности и участия в общем мире. Эти идентичные ментальные функции принято называть «здравым смыслом». «Идентичная психическая функция» теперь называлась общей только потому, что она была общей для всех. Общее, что есть 
у людей, - это не мир, а структура их умов, все же это нельзя назвать общим, поскольку, строго говоря, их разумный ум может быть только одинаковым у всех» [Там же].

15. «Понимание всегда относится к феноменальному общению мира. Феноменальный характер мира проистекает из того факта, что все события и проявления в мире в конечном счете опираются на человеческие деяния, основным признаком которых является их происхождение: а именно то, что что-то новое действительно происходит посредством человеческой деятельности, следовательно, оно отражается. Действие и понимание создают и сохраняют феноменальность мира. Понимание, направленное на событие в мире, освещает его как конец истории, начало которой в прошлом раскрыто посредством самого события. Очевидно, то, что существуют такие вещи, как начало в этом мире, что есть действие и существует что-то новое. Это понимание само по себе влияет на действие. Ибо только действие может изменить состояние мира, которое было изменено событиями, и перейти к чему-то другому и чему-то новому, то есть к концу старой и началу новой истории. Таким образом, понимание - это обещание, существующее для тех, кто будет действовать в мире после нас» [Там же. С. 182].

Таковы исходные положения Ханны Арендт о политическом мышлении. В тексте статьи они нужны для понимания значимости постановки политического мышления в центр политического понимания мира и интерпретации мира политических явлений и феноменов. При этом ясно, что приведенные выше рассуждения Х. Арендт не носят исчерпывающий характер. Многие из них более детально и расширенно прописаны и в других работах автора ${ }^{1}$. Но нельзя не согласиться с тем, что они выпукло показывают необходимость переосмысления исходных оснований и принципов как в профессиональной политической работе, так и в методологии интерпретации политических явлений, постановке образовательных и исследовательских задач.

Такой подход, с нашей точки зрения, позволит понять и правильно интерпретировать современную политическую ситуацию как ситуацию постановки новых компетенций, смены содержания образовательного стандарта и внедрения профессионального стандарта «политик». Только через проблематизацию реального профессионального опыта достижений и ошибок политика можно понять то, что для его деятельности может дать и восполнить политическое знание. Путь же дедуцирования старых и новых парадигм научного знания должен быть приостановлен применительно к миру политической действительности. Именно «тайна бытия» политического мира должна быть пере-интерпретирована мышлением, претендующим на статус мышления политического и правильным образом поставленным в реальную деятельность политика.

И в качестве заключения - иллюстрация или переход данной проблематики в организационный план действий наглядно демонстрирует схема, понимание и реализация которой возможна в нашей стране в ближайшее 10-летие (рис. 1).

\footnotetext{
${ }^{1}$ Многие аспекты политического мышления раскрыты и в других работах автора: Арендт X. Vita Activa, или о деятельной жизни. М.: АдМаргинем Пресс, 2017; Арендт Х. Опыты понимания, 1930-1954. Становление, изгнание и тоталитаризм. М.: Изд-во Института Гайдара, 2018; Арендт Х. Ответственность и суждение. М.: Издательство Института Гайдара, 2014.
} 


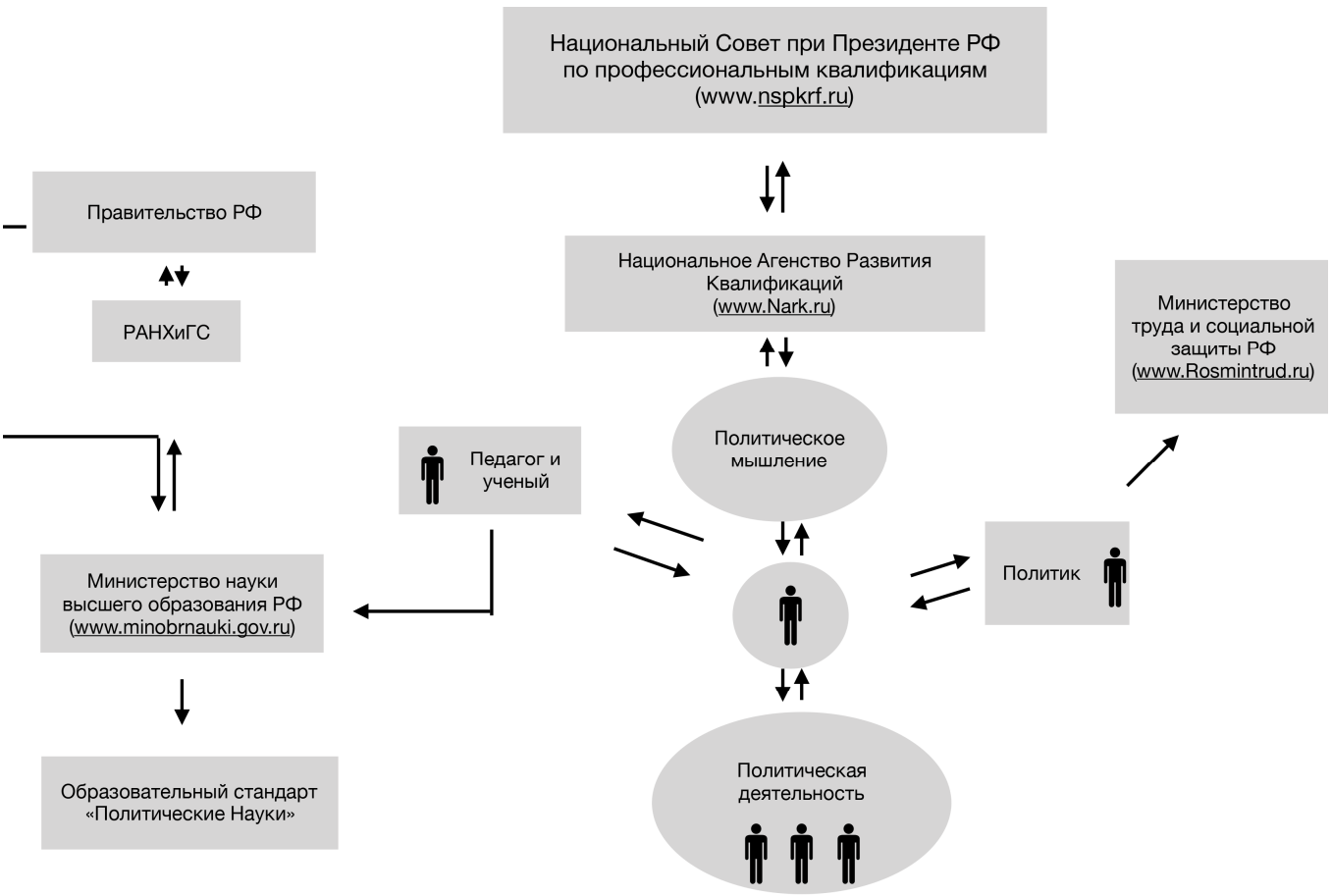

Рисунок 1. Политическая ситуация постановки новых компетенций, смены содержания образовательного стандарта и внедрения профессионального стандарта «политик»

\section{Ссылки / References}

1. Горбачев М. С. Перестройка и новое мышление для нашей страны и всего мира. М.: Политиздат, 1988.

2. Новая технологическая революция: вызовы и возможности для России / Г. И. Идрисов, В. Н. Княгинин, А. Л. Кудрин, Е. С. Рожкова // Вопросы экономики. 2018. № 4. С. 5-25.

3. Вайцзеккер Э. Фактор-5. Формула устойчивого роста. М.: АСТ-Пресс Книга, 2013.

4. Weiszacker E. Come On!: Capitalism, Short-termism, Population and the Destruction of the Planet // Springer; 1st ed. 2018 edition. 2017.

5. Daly H. The Perils of Free Trade // Scientific American. Springer Nature. 1993. November (vol. 269, № 5). P. 24-29.

6. Курцвейл Р. Эволюция разума, или Бесконечные возможности человеческого мозга, основанные на распознавании образов. М.: Эксмо, 2015.

7. Diamandis P., Kotler S. Abundance: The Future Is Better Than You Think // Free Press. February, 21. 2012.

8. Папа Римский Франциск. Энциклика Lumen Fidei. // LA SANTA SEDE. URL: http://w2.vatican.va/content/francesco/ru/encyclicals/documents/papafrancesco_20130629_enciclica-lumen-fidei.html (дата обращения: 14.08.2020) 
9. Бейтсон Г. Экология разума (сборник). М.: Захаров, 2000.

10. Maturana U., Varela F. Autopoiesis: the organization of the living. 1973. URL: https://www.semanticscholar.org/paper/Autopoiesis\%3A-the-Organization-of-the-LivingMaturana-Varela/24666f3700bb11f0b0c8d1c07249fdfa8e78af85 (дата обращения: 14.08.2020).

11. Capra F., Luigi P. The Systems View of Life: A Unifying Vision. Cambridge University Press, 2014.

12. Малахов A. «Comeon!» - юбилейный доклад Римского клуба. URL: http://malakhov.link/come-on-report (дата обращения: 14.08.2020).

13. Eisler R. The Real Wealth of Nations: Creating a Caring Economics. San Francisco: BerrettKoehler, 2007.

14. Wilber K. The Religion of Tomorrow: A Vision for the Future of the Great Traditions-More Inclusive, More Comprehensive, More Complete. Shambhala, 2018.

15. Weeramantry C. The Law in Crisis: Bridges of Understanding. London: Capemoss, 1975. Reprinted by Sarvodaya, 2001.

16. World Future Council. Voice of Future generation // Keyboard. URL: https://www.worldfuturecouncil.org/about/ (дата обращения: 14.08.2020)

17. Raskin P. Journey to Earthland: The Great Transition to Planetary Civilization. Boston: Tellus Institute, 2016.

18. Рифкин Дж. Третья промышленная революция. М. Альпина нон-фикшн, 2017.

19. Felber C. Change everything. Creating an Economy for the Common Good. November, 2019.

20. Fullerton J. B. A 'Gospel of Wealth' for the 21st Century // Alliance Magazine. June 2013.

21. Гаман-Голутвина О.В.Преодолевая методологические различия: споры о познании политики в эпоху неопределенности // Полис. Политические исследования. 2019. №5. С. 19-42.

22. Бердяев Н. Опыт парадоксальной этики. М., 2003.

23. Пятигорский А. М., Алексеев О. А. Размышляя о политике. М., 2008 // Гуманитарный портал. URL: https://gtmarket.ru/laboratory/basis/3182.

24. Ernst Vollrath, Hans Fantel. Hannah Arendt and the Method of Political Thinking Research. Vol. 44. № 1. URL: http://www.jstor.org/stable/40970278 (дата обращения: 14.08.2020). 